\title{
Comparative phenotypic characteristics of Staphylococcus aureus isolates from line and non-line associated septicaemia, CAPD peritonitis, bone/joint infections and healthy nasal carriers
}

\author{
W. I. AL-WALI, S. J. ELVIN*, C. M. MASON, A. CLARK† and H. S. TRANTER \\ Department of Medical Microbiology, Northern General Hospital, Sheffield S5 7BQ, *Centre for Applied \\ Microbiology and Research (CAMR), Porton Down, Salisbury SP4 OJG and †Department of Medical \\ Microbiology, Sheffield School of Medicine, Sheffield S10 2RS
}

\begin{abstract}
This study compared specific phenotypic and potential virulence characteristics of Staphylococcus aureus isolates from invasive infections and nasal carriers. Three hundred and sixty isolates were studied; 154 from septicaemia (69 line associated, 85 non-line), 79 from continuous ambulatory peritoneal dialysis (CAPD) peritonitis, 64 from bone/joint infections and 64 from healthy nasal carriers. The isolates were tested for production of enterotoxins (SE) A, B, C or E, toxic shock syndrome toxin-1 (TSST-1) protein $\mathrm{A}$, and also for lipolytic, proteolytic, fibrinolytic and haemolytic activities. In addition phage typing, crystal violet reaction, urease and galactose breakdown were studied. Seventy-one percent of isolates were enterotoxigenic. Production of SEA was significantly lower amongst the bone/joint isolates. Production of SEB, was lower among the control group compared with CAPD, bone/joint, and non-line septicaemia isolates. SEE production was higher among the bone/joint isolates compared with the CAPD and non-line septicaemias and production of TSST-1 was significantly higher among nasal isolates compared with isolates causing infection. Almost all of the isolates were lipolytic, with highest activity amongst nasal and bone/joint isolates. Fibrinolytic activity was similar in the five groups of isolates. Proteolytic activity ranged from 35 to $62 \%$ of isolates with the lowest frequency among septicaemia isolates. In all, 80-90\% of isolates were haemolytic, although CAPD isolates were less likely to be haemolytic. Isolates from the control and CAPD group more frequently belonged to phage group I. TSST-1 does not appear to be an important requirement for invasive infections, but SEB may be. Proteolysis and intensity of lipolysis appear to be less important in septicaemia, and haemolysis may not be important in CAPD pertonitis.
\end{abstract}

\section{Introduction}

Staphylococcus aureus is an important cause of community- and hospital-acquired infection [1,2]. It is the second most important cause of septicaemia after Escherichia coli [3]. It is also the second most common cause of intravascular line-associated infection after coagulase-negative staphylococci [4]. Although coagulase-negative staphylococci are the most important pathogens in continuous ambulatory peritoneal dialysis (CAPD) peritonitis, $S$. aureus is second in frequency and tends to be more refractory to treatment, with a high rate of relapse resulting in catheter loss [5].

Received 15 Nov. 1996; revised version accepted 18 July 1997.

Corresponding author: Dr W. I. Al-Wali.
$S$. aureus is capable of producing various toxins and extracellular products [6]. Some toxins are recognised to be associated with specific clinical conditions such as food poisoning, [7] scalded skin syndrome, [8] toxic shock syndrome [9] and the recalcitrant erythematous desquamating disorder [10]. However, the contribution of these toxins and other extracellular products is either not clear or only anecdotal in the pathogenesis of most other $S$. aureus infections. For example, in a study of staphylococcal septicaemia, enterotoxin production was higher among blood culture isolates than in nasal isolates from healthy individuals [11], but in another study, no difference in enterotoxin production was shown between two similar groups [12].

The proteolytic activity of $S$. aureus has been suggested as a virulence factor in infection [13] and 
isolates from cases of toxic shock syndrome appear to be more proteolytic than control isolates [14]. The lipolytic activity of isolates from cases of recurrent furrunculosis and pyomyositis appears to be greater than that from septicaemic isolates. However, isolates from septicaemia were reported to be more lipolytic than strains from osteomyelitis, impetigo or healthy nasal carriers [15]. Impetigo isolates have been reported to have little lipase activity [16]. Extracellular protein A was produced in greater amounts by $S$. aureus isolates from patients with post-operative wound infections [17], although in a methicillinresistant $S$. aureus (MRSA) outbreak strain, its expression was low compared with sporadic MRSA isolates [18]. With the crystal violet reaction, strains with a purple reaction (indicating non-uptake by the organism) were described as more invasive and more likely to be hospital-acquired compared to the yellow and white isolates [19].

The aim of this study was to compare these potential virulence factors and other phenotypic characteristics among a variety of $S$. aureus isolates. Unlike previous studies $[11,12,20-26]$ a large number of phenotypic characteristics of isolates from a number of well defined groups of $S$. aureus infections were studied.

\section{Materials and methods}

\section{Source of isolates}

A total of 360 isolates was investigated, comprising 296 from clinical infections and 64 from healthy nasal carriers (control group); each was isolated from a separate patient or control individual. The infections comprised septicaemias (non-intravascular line-associated, $n=85$; intravascular line-associated, $n=69$ ), CAPD peritonitis $(n=79)$ and bone/joint infections $(n=64)$.

\section{Patient groups}

A total of 154 patients with septicaemia at the Northern General Hospital, Sheffield, was studied. Clinically significant $S$. aureus septicaemia was defined as one or more positive blood cultures associated with appropriate clinical manifestations. The non-intravascular line-associated cases of septicaemia $(n=85)$ were either primary, i.e., without a detectable primary focus, or associated with various other foci, namely, pneumonia, empyema, arthroplasty-associated arthritis, native and prosthetic valve endocarditis, osteomyelitis, sternal wound infections, post-operative wound infections, skin infections, urinary tract infections and septic myositis. Of these infections, $67 \%$ were community acquired, i.e., detected within $48 \mathrm{~h}$ of admission; the remaining $33 \%$ were hospital-acquired. Of the non-intravascular line-associated infections, 11 were cases of primary septicaemia and in 74 a primary focus of infection was identified. The definition of intravascular line-associated infection was the presence of inflammation with or without discharge from the exit site and the laboratory isolation of $S$. aureus from the catheter tips or exit site swabs.

Seventy-nine $S$. aureus isolates from the peritoneal dialysate of 79 CAPD patient who presented with peritonitis were examined. Thirty strains were isolated from patients at the Renal Unit, the Northern General Hospital, Sheffield. Forty-nine were isolated from patients at the Renal Unit, Nottingham City Hospital, Nottingham. Clinical practice and patient demographics are similar in both centres. A diagnosis of $S$. aureus peritonitis was made on the basis of the presence of 100 white cells $/ \mathrm{ml}$ or more with isolation of the organism.

S. aureus isolates from 64 patients with infections of joints or bones, including patients who had undergone hip or knee prosthetic arthroplasty were studied.

\section{Control group}

A total of 64 strains of $S$. aureus was isolated from the anterior nares of 192 healthy individuals working at the Northern General Hospital. No individual was in contact with patients or had received antibiotics in the preceding 4 weeks. The distribution of these individuals was as follows: laboratory staff (57), catering service staff (21), construction workers from a hospital building site (57) and members of the administration department (57).

\section{Bacterial strains and culture media}

Isolates were stored at $-70^{\circ} \mathrm{C}$ in glycerol $15 \%$ in nutrient broth (BDH; Oxoid). They were retrieved by plating on to horse blood 5\% agar (Oxoid). Isolates were identified on the basis of a positive 'Staphytect' (Oxoid) test and DNAase production determined by multi-point inoculation.

The control strains used were NCTC 7121 ( $\alpha$ haemolysin producing), NCTC 7428 ( $\beta$-haemolysin producing), NCTC 5663 ( $\gamma$ - and $\beta$-haemolysin producing), NCTC 9715 ( $\delta$-haemolysin producing), NCTC 5655 ( $\alpha$-haemolysin but not $\beta$ - or $\gamma$-producing), strain BB ( $\beta$-haemolysin producing) strain Smith SR ( $\gamma$ haemolysin producing); NCTC 10833 (Fibrinolytic), strain FRI 722 (enterotoxin A producer), FRI S6 (enterotoxin $\mathrm{B}$ producer), FRI 361 (enteroxin $\mathrm{C}_{2}$ producer), FRI 326 (enterotoxin $\mathrm{E}$ producer) and FRI MN8 (TSST-1 producer). The NCTC strains were supplied by the National Collection of Type Cultures, CPHL, 61, Colindale Avenue, London and the FRI strains by CAMR, Porton Down.

Multi-point inoculation was used for the detection of haemolytic, fibrinolytic and lipolytic activity. One colony of each isolate was inoculated into $1 \mathrm{ml}$ of 
nutrient broth containing glucose $10 \%$ and incubated for $2 \mathrm{~h}$ in a water bath at $37^{\circ} \mathrm{C}$. Multi-point inoculation was performed on the blood-based, lipidbased and bovine fibrin agar media. Subculture of the broths on to horse blood agar was also done to confirm the purity of strains.

Isolates were cultured in New Zealand-amine broth supplemented with thiamine and riboflavine in $50-\mathrm{ml}$ Erlenmeyer flasks [27]. These were incubated at $37^{\circ} \mathrm{C}$ with continuous orbital shaking at $200 \mathrm{rpm}$ for $48 \mathrm{~h}$. An uninoculated control was included in each experiment. The culture broths were then centrifuged at $3000 \mathrm{rpm}$ for $15 \mathrm{~min}$ at $4^{\circ} \mathrm{C}$ in sterile $28-\mathrm{ml}$ screw-capped containers. The supernatant fluids were saved in 5-ml sterile containers (LIP, Shipley) and kept at $-70^{\circ} \mathrm{C}$ until tested.

\section{Detection of $S$. aureus enterotoxins and toxic shock syndrome toxin-1}

Enterotoxins A, B, C and E (SEA, SEB, SEC, SEE) and toxic shock syndrome toxin-1 (TSST-1) were detected by double sandwich ELISA [28]. The detection of all the toxins was semi-quantitative, i.e., two values were defined, $1-100 \mathrm{ng} / \mathrm{ml}$ and $>100 \mathrm{ng} / \mathrm{ml}$. To confirm the data obtained from the ELISA assays, 60 randomly selected isolates were tested by reverse passive latex agglutination (RPLA, Oxoid).

\section{Extracellular protein $A$}

Production of protein A (PrA) was detected semiquantitatively by an ELISA technique [29]. For confirmation, 60 randomly selected isolates were retested by immunoblotting with specific chicken antiprotein A [30]. Two controls of PrA with different concentrations, $1 \mathrm{ng}$ and $100 \mathrm{ng}$, were included in each experiment. By comparing the optical densities of the tested strains with the controls, positive results were quantified either as $1-100 \mathrm{ng} / \mathrm{ml}$ or $>100 \mathrm{ng} / \mathrm{ml}$.

\section{Cytolysin activity}

Sheep, rabbit, horse and human blood agar were prepared to detect the presence of cytolysin activity. In the absence of relevant antisera only general conclusions could be made about cytolysin/haemolysin activity rather than specifying whether $\alpha, \beta$, etc., were produced. The erythrocytes were washed three times in phosphate-buffered saline and then standardised as a $50 \%$ suspension before being incorporated as $5 \% \mathrm{v} / \mathrm{v}$ in agar or agarose. Sheep blood agar plates were also supplemented with $10 \mathrm{mM} \mathrm{MgSO}_{4}$, because the $\beta$ haemolysin is a magnesium dependent sphingomyelinase $\mathrm{C}$ with a marker specific for sheep erythrocytes exhibiting 'hot-cold' haemolysis [31]. Agarose $1 \% \mathrm{w} / \mathrm{v}$ was used with rabbit blood agar plates to optimise the detection of $\gamma$-cytolysin detection [32]. $\gamma$-Cytolysin is inhibited by acid polysaccharides contained in normal laboratory agar but not in purified preparations such as agarose. Multi-point inoculation was performed for all isolates, with each strain inoculated at the same time on four different blood agar media which were subsequently incubated at $37^{\circ} \mathrm{C}$ for $24 \mathrm{~h}$. The sheep blood agar was then incubated at $4^{\circ} \mathrm{C}$ for a further $4 \mathrm{~h}$. The haemolytic activity was detected by the presence of complete clearing of a zone $\geqslant 5 \mathrm{~mm}$ in diameter. All the experiments were repeated three times on three different occasions and a mean result, i.e., zone diameter was calculated.

\section{Lipolytic activity}

Lipolytic activity was detected by the use of three different media: tributyrin to detect lipase, egg-yolk to detect lipase and phospholipase, and Tween 80 agar media to detect esterases. The tributyrin agar was obtained pre-prepared from Oxoid. It is a soluble homogenate of nutrient glyceryl tributyrate. A positive reaction consisted of a zone of clearing in the opaque medium around the inocula [33]. Egg-yolk agar medium was prepared as described earlier [34]. Detection of opalescence underlying the inocula or zones of clearing and opalescence around inocula, and a pearly layer overlying inocula is considered to indicate the presence of lipases. Tween 80 agar $0.1 \%$ plates were prepared as described previously [35]. A positive reaction consisted of opacification around the inoculum and the zone diameter was recorded. The agar plates were incubated aerobically at $37^{\circ} \mathrm{C}$ for $24 \mathrm{~h}$ and then read. All the experiments were repeated three times on different occasions.

\section{Proteolytic activity}

Skimmed milk agar (Difco) 10\% was used to detect proteolytic activity [36] as indicated by clearing around inocula. The experiments were repeated three times on different occasions.

\section{Fibrinolytic activity}

Staphylokinase production was detected by the use of bovine fibrin agar (Hoechst UK Ltd, Hounslow) incorporating dog plasma (Laboratories Ltd, Burnhouse) $0.5 \% \mathrm{v} / \mathrm{v}$ in parallel with a control plate without the plasminogen source to exclude non-specific proteolytic activity [37]. All the experiments were repeated three times for reproducibility. A positive result was demonstrated by clearing around the inocula which was not present in the control plate.

\section{Crystal violet reaction}

Crystal violet agar was prepared by incorporating crystal violet (BDH/Merck Ltd, Lutterworth) 1 in 10000 in nutrient agar. The plates were inoculated in the form of 5-mm diameter inocula [19] incubated aerobically for $24 \mathrm{~h}$ at $37^{\circ} \mathrm{C}$ and then examined for three colour reactions; purple, yellow or white, which 
indicate three phenotypic markers. All the experiments were performed three times.

\section{Galactose and urea breakdown}

The production of enzymes that break down galactose and urea was detected by incorporating galactose $1 \%$ $\mathrm{w} / \mathrm{v}$ and urea $1 \% \mathrm{w} / \mathrm{v}$ into agar slopes in 5-ml screwcapped bottles inoculating them with control or test isolates, incubating overnight and inspecting change of indicator colour.

\section{Bacteriophage typing}

Bacteriophage typing was done as described by Blair and Williams [38]. The international basic set of bacteriophages for typing $S$. aureus was supplied by the Central Public Health Laboratory, Colindale, London. The isolates were divided into phage groups I, II, III and $\mathrm{V}$ [39] on the basis of the susceptibility patterns to the set of phages at the routine test dilution (RTD). Group V isolates comprised those lysed by phage 94 , 96 or both. Phage 95 was put in a separate group apart from I, II, III and V and those that were not lysed were put into the non-typable group.

\section{Statistical analysis}

Analysis of variance, multiple and two by two $\chi^{2}$ test, Fisher's exact test and Yate's test were used to analyse differences in toxin, extracellular products and other phenotypic characteristics among the isolates. A p value of $<0.05$ was considered to indicate statistical significance [40].

\section{Results}

\section{Enterotoxin and TSST-1 production}

Enterotoxins were detected in $57,74,68,78$ and $77 \%$ of the five groups of isolates, i.e., control, non-lineassociated septicaemia, line-associated septicaemia CAPD and bone/joint infections respectively with an overall mean frequency of $71 \%$. SEA production (Fig. 1) amongst bone/joint isolates was significantly lower than amongst control, non-line and line isolates $(p=0.02)$. SEB production was lower in the control group than in the non-line, CAPD and bone/joint groups, $(p=0.011-0.048)$.

The production of SEE was statistically greater amongst bone/joint results (Fig. 2) compared with non-line isolates $(p<0.02)$ and the CAPD isolates $(p<0.007)$. TSST-1 was detected in $62 \%$ of control isolates and $31 \%$ of test isolates $(p<0.005)$ and there was also a statistical difference between the non-line results and those of the other five groups $(p<0.001)$. Combinations of toxin production (enterotoxins and TSST-1) are presented in Table 1.

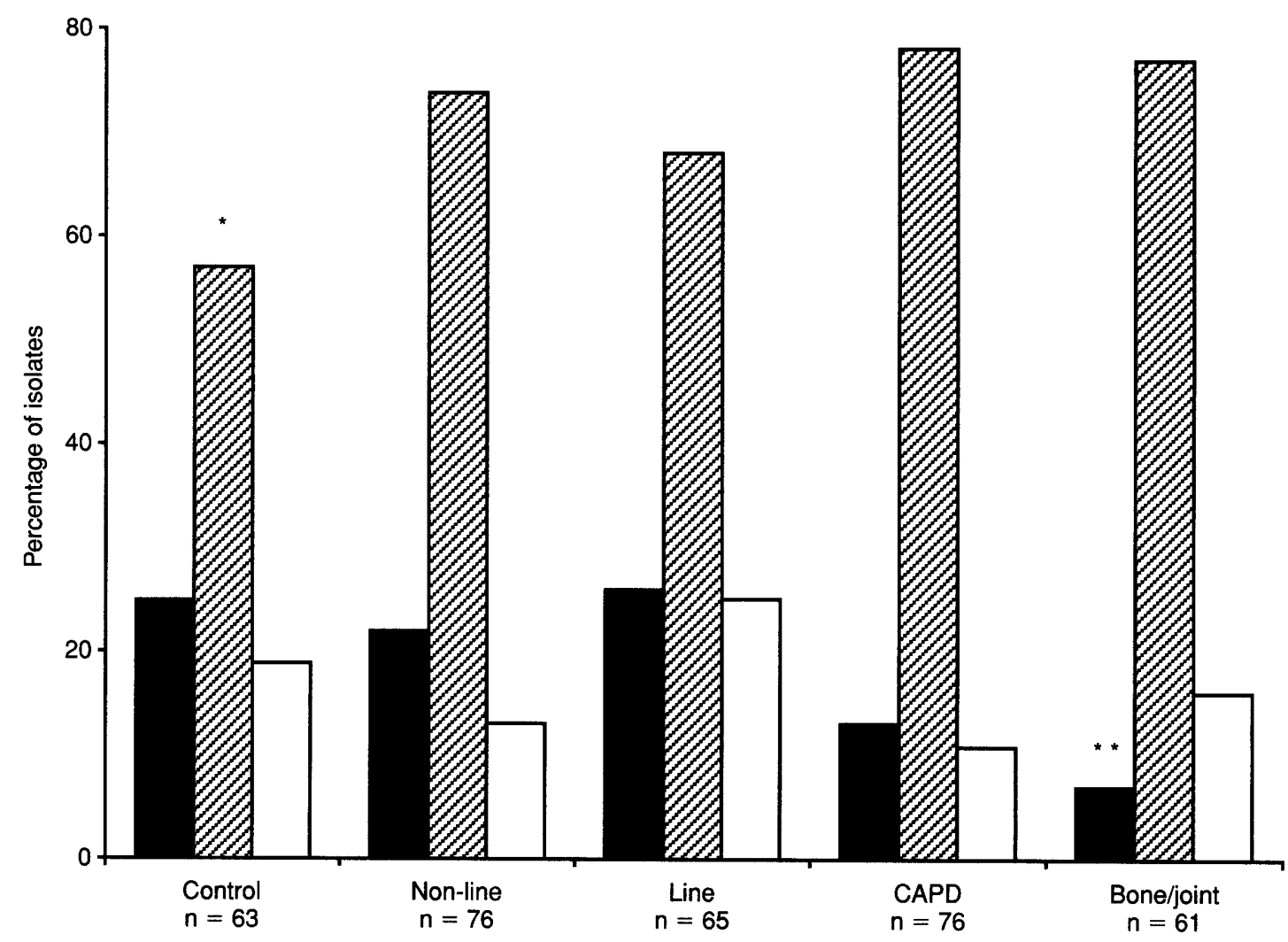

Fig. 1. Enterotoxins A ( $\square)$, B ( $\square)$ and C ( $\square)$ production amongst the five groups of isolates. ${ }^{*} p=0.011-0.048$, ${ }^{* *} \mathrm{p}=0.004-0.015$. 


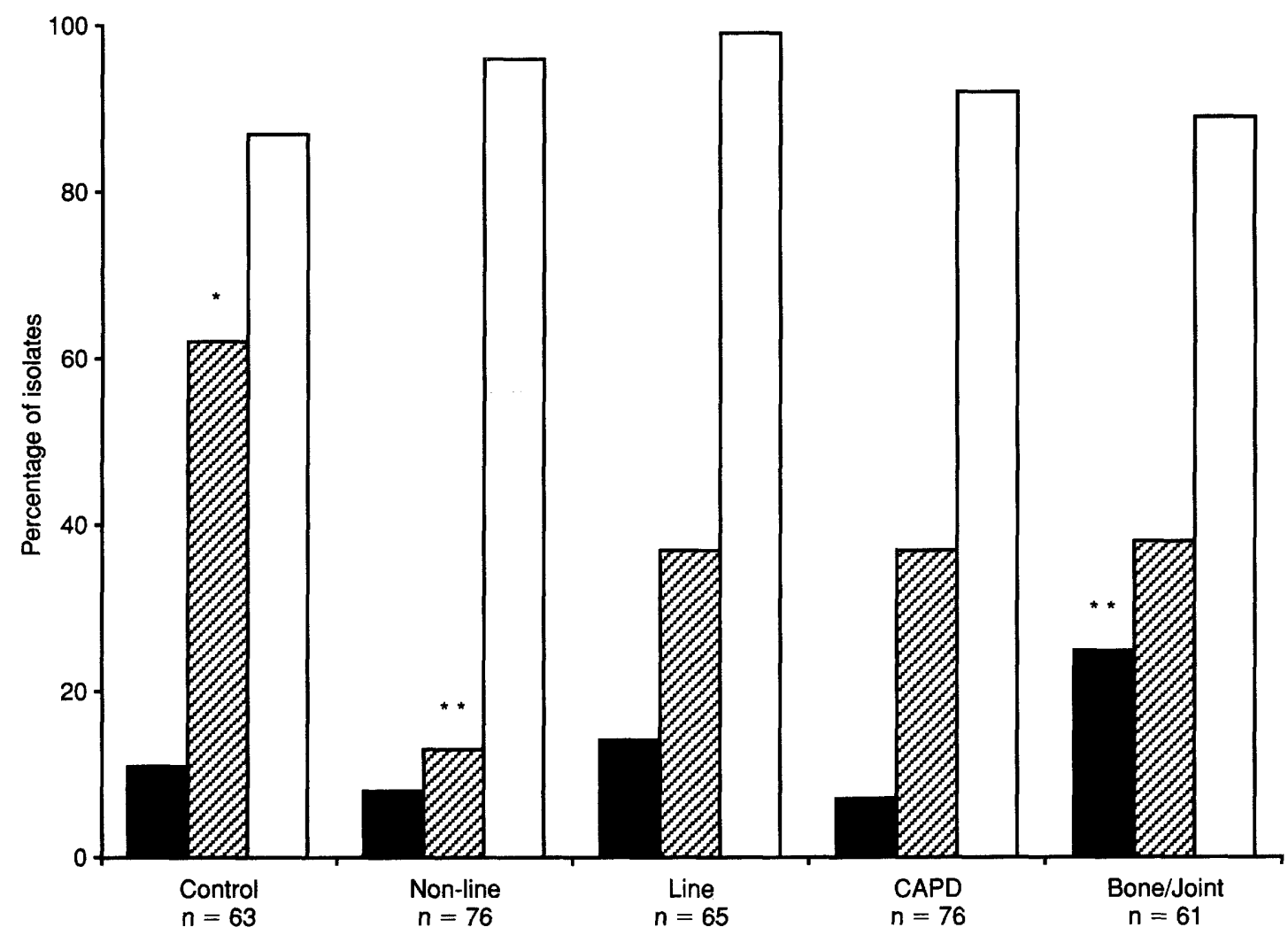

Fig. 2. Enterotoxin E ( $\square$ ), toxic shock syndrome toxin-1 (TSST-1) ( $\square$ ) and extracellular protein A ( $\square$ ) production amongst the five groups of isolates. ${ }^{*} \mathrm{p}=0.011-0.048,{ }^{* *} \mathrm{p}=0.004-0.015$.

Table 1. Combinations of toxin production (TSST-1, SEA, SEB, SEC and SEE) among the five groups of isolates

\begin{tabular}{lccccc}
\hline & \multicolumn{5}{c}{ Number of toxins } \\
\cline { 2 - 6 } $\begin{array}{l}\text { Number of } \\
\text { toxins produced }\end{array}$ & Control & $\begin{array}{c}\text { Non-line- } \\
\text { associated }\end{array}$ & $\begin{array}{c}\text { Line- } \\
\text { associated }\end{array}$ & CAPD & Bone/joint \\
\hline One & 33 & 52 & 44 & 42 & 38 \\
Two & 31 & 27 & 25 & 37 & 34 \\
Three & 20 & 18 & 19 & 15 & 18 \\
Four or more & 16 & 3 & 12 & 6 & 10 \\
\hline
\end{tabular}

The concentration of toxins produced by all isolates was between 1 and $100 \mathrm{ng} / \mathrm{ml}$, except for the line isolates where 10 of 17 SEA producers produced concentrations $>100 \mathrm{ng} / \mathrm{ml}$; the same was true for 6 of 16 isolates for SEC and for 9 of 24 isolates for TSST-1. In the control group, 6 of 12 were high producers of SEC. In the non-line group, 4 of 10 were high producers of TSST-1. In the CAPD category 4 of 10 were high producers of SEA.

\section{Protein A production}

Extracellular protein A production was detected in the majority of isolates and ranged from $1 \mathrm{ng} / \mathrm{ml}$ to $>100 \mathrm{ng} / \mathrm{ml}$ (Fig. 2).

\section{Haemolysin production}

The great majority of the isolates was haemolytic on at least one or more blood agar media (Fig. 3). Overall, CAPD isolates were significantly less haemolytic than the bone/joint isolates $(p=0.012)$ and isolates from the control group were less frequently haemolytic than bone/joint isolates $(p=0.033)$. The CAPD isolates were less frequently haemolytic on horse and human blood agar than the other groups $(p<0.05)$.

\section{Lipolytic activities}

On tributyrin agar all of the isolates, except three, were lipolytic. There were differences between control and bone/joint isolates and the non-line, line and CAPD 

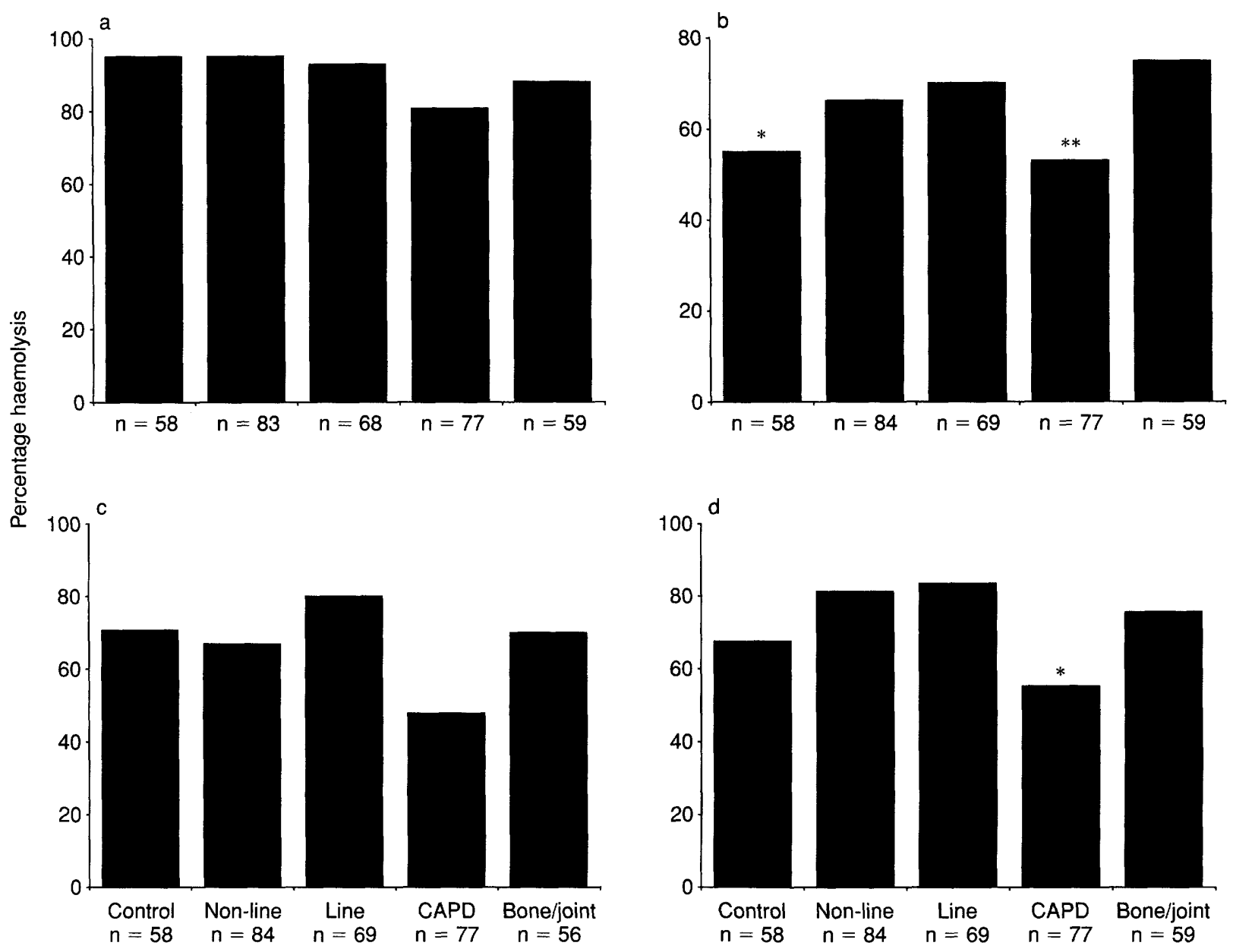

Fig. 3. Haemolytic activities amongst the five groups of isolates on rabbit, sheep, horse and human red blood cells $(\mathrm{RBC})$ expressed as percentages. a, rabbit: b, sheep, ${ }^{*} \mathrm{p}=0.033,{ }^{* *} \mathrm{p}=0.012 ; \mathbf{c}$, horse, ${ }^{*} \mathrm{p}=0.0007-0.027 ; \mathrm{d}$, human ${ }^{*} \mathrm{p}=0.0006-0.017$.

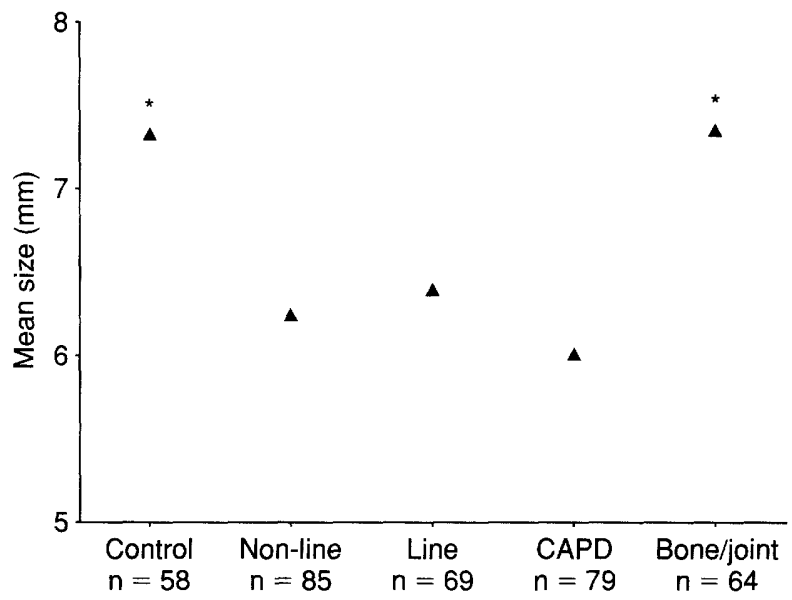

Fig. 4. Lipolytic activity on tributyrin agar medium (mean zone size of clearing in $\mathrm{mm}$ ) of the five groups of isolates. ${ }^{*} \mathrm{p}=<0.01$.

isolates ( $p=<0.01$ ) (Fig. 4). On Tween agar, positive reactions for esterase were observed in $73,84,74,77$ and $85 \%$ of the isolates in the five groups, respectively, with no significant difference. Finally, on egg-yolk agar the great majority $(>80 \%)$ produced lipase and phospholipase with no demonstrable difference between the groups.

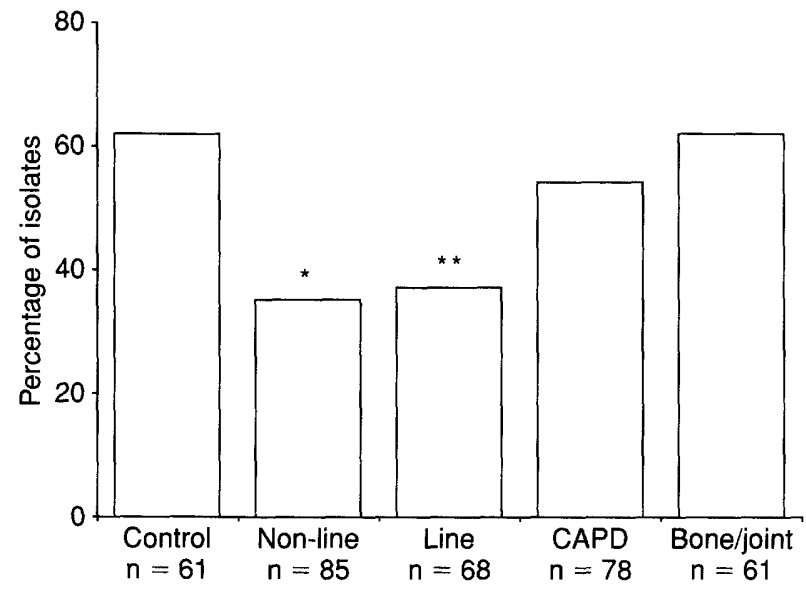

Fig. 5. Proteolytic activity amongst the five groups of isolates. ${ }^{*} \mathrm{p}=0.002-0.02,{ }^{* *} \mathrm{p}=0.005-0.046$.

\section{Proteolysis}

Sixty-two percent of control isolates and 35, 37, 54 and $57 \%$ of the isolates from infection, respectively, produced proteases (Fig. 5). The non-line and lineassociated septicaemia isolates were less frequently proteolytic than the other groups. 


\section{Fibrinolytis crystal violet reaction, galactose and urea breakdown}

There were no significant differences amongst the five groups in these tests.

\section{Bacteriophage typing}

There was a higher proportion of isolates amongst the control isolates $(p<0.01-0.008)$ and CAPD isolates $(p<0.05-0.022)$ lysed by Group I phages, but otherwise the distribution of phage types was similar between the groups and between Nottingham and Sheffield.

\section{Discussion}

The majority of isolates in this study were enterotoxigenic, which differs from other studies where RPLA was used for toxin detection $[11,12,20]$. This may be because ELISA is more sensitive than the techniques used in earlier studies. The most significant finding in this study is the greater proportion of control isolates producing TSST-1 (62\%) compared with isolates from invasive infection (13-38\%). Again, this differs from other studies which have shown no difference in TSST1 production between septicaemia and nasal isolates $[11,12]$. This observation was even more significant with non-intravascular line-associated septicaemia isolates, in which there were no foreign bodies, i.e., catheters, to provide a portal of entry.

TSST-1 has potent mitogenic activity for human $T$ lymphocytes [41], leading to the release of many cytokines, including $\gamma$-interferon, interleukin-1 (IL-1), IL-2, IL-3, IL-6 and TNF-alpha and -beta. Monocytes and macrophages may also be induced by TSST- 1 to release IL-1 and TNF-alpha in addition to those released by $\mathrm{T}$ lymphocytes [42]. Furthermore, TSST-1 has been shown to have harmful effects by its inhibitory effect on the mobilisation of polymorphonuclear leucocytes to sites of infection mediated by TNF production [43], an arthritogenic effect on mice with increased IL-2 receptor-expressing cells in the inflamed synovium, and possible association with glomerulonephritis following MRSA infection [44]. However, no study to date has confirmed the association of such effects with TSST-1-producing $S$. aureus septicaemia.

Some workers have demonstrated that the genes encoding TSST- 1 and SEB are located in close proximity on the chromosome and this may affect the expression of SEB $[45,46]$. In this study SEB was produced more frequently amongst invasive isolates than in controls. SEB has the same immunomodulatory effect as TSST-1 as other staphylococcal enterotoxins. Animal studies have shown SEB to damage renal, hepatic and vascular endothelium in addition to having a thrombocytopenic hypovolemic effect [47]. Murine hepatic injury was also demonstrated by INF- $\alpha$ and INF- $\gamma$ production induced by SEB [48]. It has also been suggested that SEB contributes to the pathogenesis of various skin diseases by either locally activating $\mathrm{T}$ cells or enhancing keratinocyte production of cytokines [49]. Furthermore, other studies have shown SEB to be implicated in wound infections and in hepatic injury $[21,50]$. There was no difference in the frequency of SEC production among the isolates in the present study. Sugiyama and McKissic have observed leucopenia in monkeys following administration of SEC by the intragastric or intravenous route [51]. SEC appeared to be implicated in diarrhoeal diseases including post-operative enteritis caused by MRSA [22]. Other studies report high prevalence in pyogenic skin disease [52], in renal tissues from autopsies of cases of sudden infant death [53], and in glomerulonephritis following MRSA infection by polyclonal activation of IgG and IgA necessary for the development of nephritis and vasculitis [54].

At the genetic level these toxins are encoded by separate genes. The synthesis of such toxins is controlled by regulatory RNA molecule, RNA III, encoded by the agr (accessory gene regulator) locus [55] but the expression of these genes is not identical. It has been shown that SEA and SED are mainly produced during exponential growth, while extracellular accumulation of SEB, SEC and TSST-1 is maximal during the transition to the stationary phase [56]. The differences with respect to agr regulation and time of maximal toxin production relative to growth phase suggest that there are conditions in the environment that may favour production of one type of toxin rather than the other. It has also been suggested that specific conditions and other factors that influence their expression may contribute to the fact that certain types of toxins are more frequently related to each other [56]. For example, the association of SEB and SEC with non-menstrual toxic shock syndrome is more often encountered than SEA, and SEA is more often seen in association with foodpoisoning outbreaks than SEB and SEC. Finally, although it is recognised that the expression of toxins and other factors in vitro may not necessarily reflect the situation in vivo, all the laboratory experiments in this study were conducted under the same cultural and procedural conditions. This also includes storage conditions, except for some of the CAPD isolates, obtained from Nottingham, which were stored in a different medium, i.e., horse serum. However, these strains were subsequently stored in the same medium as the other isolates, i.e., glycerol in nutrient broth.

On rabbit blood agar there was no difference in haemolysis amongst the different groups as this indicates the presence of $\alpha$-toxin which is produced by the majority of $S$. aureus isolates [57]. When sheep, horse and human blood agar were used to assess haemolysis, the CAPD strains were less frequently haemolytic, indicating that there is a lower 
production of $\beta$-, $\gamma$ - and $\delta$-cytolysins. It appears that these cytolysins alone or in combination play less of a role in the pathogenesis of $S$. aureus CAPD peritonitis or that a component of the peritonitis dialysate fluid has a suppressive effect on their expression. The haemolysins or cytolysins that damage the cell membranes of erythrocytes and other cells have been studied extensively in animal models [58-61]. In human infections $58 \%$ of septicaemic isolates produced $\alpha$-cytolysin [26], whereas in another study no difference in the production of cytolysins was demonstrated between septicaemic isolates and those from healthy nasal carriers. In another study of septicaemic patients there was no evidence that $\beta$-cytolysin had contributed to the invasiveness of infecting $S$. aureus strains [26].

The genes encoding the synthesis of cytolysins are controlled by the same regulatory RNA molecule, RNA III, which controls the synthesis of other toxins and virulence factors. What was previously discussed (vide supra) regarding the factors affecting the expression of the enterotoxin genes would also apply to the cytolysins. The gene encoding the $\gamma$-cytolysins was detected in $99 \%$ of 309 randomly selected isolates by oligonucleotide probes [62] but the aim of this study was to look for the phenotypic activity on the various animal red blood cells rather than identifying the individual cytolysins, as the latter would have required the use of specific anti-cytolysin antibodies.

The lipolytic activity of the isolates was tested with three different types of media to detect lipases, esterases and phospholipases. There appeared to be no difference in the frequency of production of these enzymes among the five groups. However, the control and bone/joint isolates appeared to be more lipolytic on tributyrin agar than the septicaemic and CAPD isolates. This may be due to the host environment, which may not encourage the production of greater amounts of lipase. It is also possible that organisms may need lipase for survival in an environment which contains lipids such as the anterior nasal cavity and bone/joint tissue. Purified $S$. aureus lipase decreases chemotactic and phagocytic activity and intracellular killing in human granulocytes [63]. Proteolytic activity amongst septicaemic strains was lower than amongst the other isolates, including the control group, suggesting that proteolytic enzymes may not be expressed in a blood milieu. However, the more intense quantitative production of these enzymes by the bone/joint isolates suggest a possible role in the pathogenesis of these infections. Proteinases of $S$. aureus have been shown to have an effect on the lymphoproliferative response [64], chemotaxis [65], clearance of IL-4 [66] and inactivation of INF- $\gamma$ [67]. Caseinase (i.e., proteinase)-producing $S$. aureus strains have been shown to be more virulent than mutant deficient strains [68]. Strains isolated from cases of toxic shock syndrome were found to be more proteolytic than other infections [69] and similar proteolytic activities were observed amongst isolates causing toxic epidermal necrolysis, impetigo [8], pneumonia, and from nasopharyngeal carriers [70]. In this study the results of proteolytic activity of the isolates were reproducible, similar to the study by Arai et al. [71], who have shown the proteolytic activity of MRSA to be reproducible even after 50 passages.

The purple reaction with the crystal violet test was the most common finding, as reported elsewhere [19, 72]. The proportions of isolates with the yellow and white reactions was lower and there was no difference in the pattern of reactions amongst the five categories. It has been reported [19] that invasive and nosocomial isolates are more likely to be purple than other colonisers. This was not observed in the present study, where the control group had a higher percentage of purple isolates, although this did not reach statistical significance.

Bacteriophage typing was done for two reasons, firstly to see whether there was any difference in phage type patterns among the groups, and secondly to confirm as a control tool that that there were no strains predominant in one group and hence perhaps accounting for the increased frequency of the phenotypic characteristic investigated. However it was observed that phage group I was significantly more represented among control and CAPD isolates, but there was no clustering of individual subgroup phage patterns in these groups.

In conclusion, TSST-1 does not appear to be an important factor in invasive infections, but SEB may be significant. Nasal colonisers and bone/joint isolates were more frequently proteolytic and more intensely lipolytic. The properties of proteolysis and the intensity of lipolysis appear to be less important in septicaemia isolates, and haemolysis appears to be less important in CAPD peritonitis.

We are grateful to the Northern General Hospital Research Committee for its financial support (Grant no. 65 and 116) and to Drs P. Norman, P. Zadik, R. Spencer and R. Marples for valuable discussion, Professor R. Finch for supplying isolates and Mrs C. Nicol and $\mathrm{Mr} \mathrm{K}$. Bennet for their technical assistance in phage typing. We also thank Mr J. Blight for statistical advice, volunteers at the Northern General Hospital for providing nasal swabs, and finally Mrs S. Henson for typing the manuscript.

\section{References}

1. Sheagren JN. Staphylococcus aureus. The persistent pathogen. $N$ Engl $J$ Med 1984; 310: 1368-1373, 1437-1442.

2. Eykyn SJ, Grandsden WR, Phillips I. The causative organisms of septicaemia and their epidemiology. J Antimicrob Chemother 1990; 25 Suppl. C 41-58.

3. Gemmell CG. The staphylococcus - new features 100 years after its discovery. $J$ Infect $1982 ; 4: 5-15$.

4. Elliot TSJ. Line-associated bacteraemias. CDR Rev 1993; 3: R91-R96.

5. Al-Wali W, Baillod R, Brumfitt W, Hamilton-Miller JMT. 
Differing prognostic significance of reinfection and relapse in CAPD peritonitis. Nephrol Dial Transplant 1992; 7: 133-136.

6. Tranter HS, Brehm RD The detection and aetiological significance of staphylococcal enterotoxins. Rev Med Microbiol 1994; 5: 56-64

7. Wieneke AA, Roberts D, Gilbert RJ. Staphylococcal food poisoning in the United Kingdom, 1969-90. Epidemiol Infect 1993; 110: 519-531.

8. Gemmell CG. Staphylococcal scalded skin syndrome. $J$ Med Microbiol 1995; 43: 318-327.

9. Crass BA, Bergdoll MS. Toxin involvement in toxic shock syndrome. $J$ Infect Dis 1986; 153: 918-926.

10. Cone LA, Woodard DR, Byrd RG, Schulz K, Kopp SM, Schlievert PM. A recalcitrant, erythematous, desquamating disorder associated with toxin-producing staphylococci in patients with AIDS. $J$ Infect Dis 1992; 165: 638-643.

11. Humphreys $\mathrm{H}$, Keane $\mathrm{CT}$, Hone $\mathrm{R}$ et al. Enterotoxin production by Staphylococcus aureus isolates from cases of septicaemia and from healthy carriers. $J$ Med Microbiol 1989 ; 28: $163-172$.

12. Røder BL, Eriksen NHR, Nielsen LP, Slotsbjerg T, Rosdahl VT, Espersen F. No difference in enterotoxin production among Staphylococcus aureus strains isolated from blood compared with strains isolated from healthy carriers. $J$ Med Microbiol 1995; 42: 43-47.

13. Hasegawa N, Kondo I. Isolation and virulence of a caseinaseand bound coagulase- deficient mutant of Staphylococcus aureus BB. J Infect Dis 1984; 149: 538-543.

14. Todd JK, Franco-Buff A, Lawellin DW, Vasil ML. Phenotypic distinctiveness of Staphylococcus aureus strains associated with toxic shock syndrome. Infect Immun 1984; 45: 339-344.

15. Rollof J, Hedstrom A, Nilsson-Ehle P. Lipolytic activity of Staphylococcus aureus strains from disseminated and localized infections. Acta Path Microbiol Immunol Scand Sect B 1987; 95: 109-133.

16. Hedstrom SA, Nilsson-Ehle P. Trioleoylglycerol lipolysis by Staphylococcus aureus strains from recurrent furunculosis, pyomyositis, impetigo and osteomyelitis. Acta Path Microbiol Immunol Scand Sect B Microbiol 1983; 91: 169-173.

17. Chernevskaia OM, Zavarukhina MA, Ermoling GB. Variability of the pathogenicity traits of populations of staphylococci in a surgical hospital. Zh Mikrobiol Epidemiol Immunobiol 1985; 7: 29-32.

18. Roberts JI, Gaston MA. Protein A and coagulase expression in epidemic and non-epidemic Staphylococcus aureus. $J$ Clin Pathol 1987; 40: 837-840.

19. Freeman R, Hudson SJ, Burdess D. Crystal violet reactions of fresh clinical isolates of Staphylococcus aureus from two British hospitals. Epidemiol Infect 1990; 105: 493-500.

20. Lehn N, Schaller E, Wagner H, Kronke M. Frequency of toxic shock syndrome toxin and enterotoxin producing clinical isolates of Staphylococcus aureus. Eur J Clin Microbiol Infect Dis 1995; 14: 43-46.

21. Adesiyun AA, Lenz W, Schaal KP. Phage susceptibility, enterotoxigenicity and antibiograms of Staphylococcus aureus strains isolated from human wounds and diarrhoea. Int $J \mathrm{Med}$ Microbiol Virol Parasitol Infect Dis 1992; 277; 250-259.

22. Takesue $\mathrm{Y}$, Yokoyama $\mathrm{T}$, Kodama $\mathrm{T}$ et al. A study on postoperative enteritis caused by methicillin-resistant Staphylococcus aureus. Surg Today 1993; 23: 4-8.

23. Kimura A, Iqarashi H, Ushioda H, Okuzumi T. Epidemiological study of Staphylococcus aureus isolated from the Japanese National University and Medical College Hospitals with coagulase typing and production of enterotoxins and toxic shock syndrome toxin-1. Kansenshogaku Zasshi 1992; 66: 1543-1549.

24. Jordens JZ, Duckworth GJ, Williams RJ. Production of 'virulence factors' by 'epidemic' methicillin-resistant Staphylococcus aureus in vitro. $J$ Med Microbiol 1989; 30: 245-252.

25. Naidu S, Rao PN, Rajyalakshmi K, Naidu AS. Incidence of enterotoxin producing Staphylococcus aureus among pyogenic skin infections. J Hyg Epidemiol Microbiol Immunol 1989; 33 277-282.

26. Christensson B, Heström SA. Biochemical and biological properties of Staphylococcus aureus septicaemia strains in relation to clinical characteristics. Scand J Infect Dis 1986; 18: 297-303.

27. Reynolds D, Tranter HS, Sage R, Hambleton P. Novel method for purification of staphylococcal enterotoxin A. Appl Environ
Microbiol 1988; 54: 1761-1765.

28. Modi NK, Rose SA, Tranter HS. The effects of irradiation and temperature on the immunological activity of staphylococcal enterotoxin A. Int J Food Microbiol 1990; 11: 85-92.

29. Larsson A, Wejaker PE, Sjoquist. Chicken anti-protein A for the detection and capturing of protein A from Staphylococcus aureus in the presence or absence of mammalian IgG. Hybridoma 1992; 11: 239-243.

30. Towbin H, Staehelin T, Gordon J. Electrophoretic transfer of proteins from polyacrylamide gels to nitrocellulose sheets: procedure and some applications. Proc Natl Acad Sci USA 1979; 76: 4350-4354.

31. Mollby $R$. Isolation and properties of membrane damaging toxins. In: Easmon CSF, Adlam $\mathrm{C}$ (eds) Staphylococci and staphylococcal infections, vol 2. The organism in vivo and in vitro. London Academic Press 1983: 619-669.

32. Carlson EC. A $\mathrm{CO}_{2}$-enhanced hemolytic activity of Staphylococcus aureus associated with toxic shock syndrome: inhibition by agar. J Infect Dis 1986; 154: 186-188.

33. Lawrence RC, Fryer TF, Reiter B. Rapid method for the quantitative estimation of microbiol lipases. Nature 1967; 25: 1264-1265.

34. Lundbeck $\mathrm{H}$, Tirunarayanan $\mathrm{MO}$. Investigation on the enzymes and toxins of staphylococci. Study of the 'egg yolk reaction' using an agar plate assay method. Acta Pathol Microbiol Scand 1966; 68: 123-134.

35. Rollof J, Hedstrom SA, Nilsson-Ehle P. The Tween 80 reaction does not correlate to triglyceride lipase production of Staphylococcus aureus. APMIS 1988; 96: 732-734.

36. Collee JG, Duguid JP, Fraser AG, Marmion BP. Mackie and McCartney's Practical medical microbiology 3rd edn, vol 2. Tests for identification of bacteria. Edinburgh, Churchill Livingstone. 1989: 141-160.

37. Devriese LA, van de Kerckhove. A comparison of methods used for testing staphylokinase (fibrinolysin) production in Staphylococcus strains. Antonie van Leuwenhoek 1980; 46: 457-465.

38. Blair JE, Williams REO. Phage typing of staphylococci. Bull Wld Hlth Organ 1961; 24: 771-784.

39. Parker MT. The significance of phage-typing patterns in Staphylococcus aureus. In: Easmon CSF, Adlam C (eds) Staphylococci and staphylococcal infections, vol 1. Clinical and epidemiological aspects. London, Academic Press. 1983: $33-62$.

40. Altman GA. Comparing groups - categorical data. Comparing groups - continuous data. In: Altman GA. Practical statistics for medical research. London, Chapman and Hall. 1995: 179-223, 229-272.

41. Peavy DL, Adler WH, Smith RT. The mitogenic effects of endotoxin and staphylococcal enterotoxin B on mouse spleen cells and human peripheral lymphocytes. J Immunol 1970: 105: $1453-1458$.

42. Fleming SD, Iandolo JJ, Chapes SK. Murine macrophage activation by staphylococcal enterotoxins. Infect Immun 1991; 59: 4049-4055.

43. Fast DJ, Schlivert PM, Nelson RD. Nonpurulent response to toxic shock syndrome toxin-1 producing Staphylococcus aureus. Relationship to toxin-stimulated production of tumor necrosis factor. $J$ Immunol 1988; 140: 949-953.

44. Koyama A, Kobayashi M, Yamaguchi N et al. Glomerulonephritis associated with MRSA infection: a possible role of bacterial superantigen. Kidney Int 1995; 47: 207-216.

45. De Boer ML, Chow AW. Toxic shock syndrome toxin-1 producing Staphylococcus aureus isolates contain the staphylococcus enterotoxin B. $J$ Infect Dis 1994; 170: 818-827.

46. Lee VTP, Chang AH, Chow AW. Detection of staphylococcal enterotoxin B among toxic shock syndrome (TSS) and nonTSS-associated Staphylococcus aureus isolates. J Infect Dis 1992; 116: 911-915.

47. Bergdoll MS. Enterotoxins. In: Easmon CSF, Adlam C (eds) Staphylococci and staphylococcal infections, vol 2. The organism in vivo and in vitro. London, Academic Press. 1983; 559-598.

48. Nagaki M, Muto $\mathrm{Y}$, Ohnish $\mathrm{H}$ et al. Hepatic injury and lethal shock in galactosamine-sensitized mice induced by the superantigen staphylococcal enterotoxin B. Gastroenterology 1994; 106: $450-458$.

49. Tokura Y, Yagi J, O'Malley $\mathrm{M}$ et al. Superantigenic staphylococcal exotoxins induce T-cell proliferation in the 
presence of Langerhan cells on class II-bearing keratinocytes and stimulate keratinocytes to produce T-cell activating cytokines. $J$ Invest Dermatol 1994; 102: 31-38.

50. Nagaki M, Muto Y, Ohnishi $\mathrm{H}$ et al. Hepatic injury and lethal shock in galactosamine-sensitized mice induced by the superantigen staphylococcal enterotoxin B. Gastroenterology 1994; 106: $450-458$.

51. Sugiyama H, McKissic EM, Bergdoll MS Heller B. Enhancement of bacterial endotoxin lethality by staphylococcal enterotoxin. $J$ Infect Dis 1964; 114: 111-118.

52. Naidu S, Rao PN, Rajyalakshimi K, Naidu AS. Incidence of enterotoxin producing Staphylococcus aureus among pyogenic skin infections. J Hyg Epidemiol Microbiol Immunol 1989; 33: 277-282.

53. Telford DR, Morris JA, Hughes $\mathrm{P}$ et al. The nasopharyngeal bacterial flora in sudden infant death syndrome. J Infect 1989; 18: $125-130$.

54. Koyama A, Kobayaski M, Yamaguchi $\mathrm{N}$ et al. Glomerulonephritis association with MRSA infection: a possible role of bacterial superantigen. Kidney Int 1995; 47: 207-216.

55. Arvidson S. Genetic loci controlling the expression of virulence genes in Staphylococcus aureus. Eighth International Symposium on Staphylococci and Staphylococcal Infections, France 1996 (Abstract).

56. Betley MJ, Borst EW, Regassa LB. Staphylococcal enterotoxins, toxic shock syndrome toxin and streptococcal pyrogenic exotoxins: a comparative study of their molecular biology. In: Fleisher B (ed) Biological significance of superantigens, vol 55. Clinical immunology. Basel, Karger. 1992: 1-35.

57. Christensson B, Hadstrom SA, Kronvall G. Antibody response to alpha- and beta-hemolysin from Staphylococcus aureus in patients with staphylococcal infections and in normals. Acta Pathol Microbiol Immunol Scand B 1983; 91: 351-356.

58. Rogolsky M. Nonenteric toxins of Staphylococcus aureus. Microbiol Rev 1979; 43 320-360.

59. Weigershausen B. On the pharmacology of staphylococcal toxin (Wood 46). The effect of staphylococcal toxin on the isolated heart, auricles and vessels of various species. Act Biol Med Ger 1962; 9; 517.

60. Takeuehi S, Suto T. Behaviours of a vigorous proteaseproducing strain of Staphylococcus aureus in the skin tissue of mice. Jpn J Microbiol 1976; 20: 155-162.

61. Kapral FA, O'Brien AD, Ruff PD, Drugan WJ. Inhibition of water absorption in the intestine by Staphylococcus aureus delta-toxin. Infect Immun 1976; 13: 140-145.

62. Prevost G, Couppie P, Prevost P et al. Epidemiological data on Staphylococcus aureus strains producing synergohymenotropic toxins. J Med Micribiol 1995: 42: 237-245.

63. Rollof J, Braconier JH, Soderstrom C, Nilson-Ehle P. Interference of Staphylococcus aureus lipase with human granulocyte function. Eur J Clin Microbiol Infect Dis 1988; 7: $505-510$.

64. Porwiit-Bobr Z. Modulation of lymphocytes and immunoglobulins by serine proteinase of Staphylococcus aureus. Med Dosw Mikrobiol 1993; 45: 37-40.

65. Baran K, Midzobrodzki J, Porwit-Bobr Z. Preliminary estimation of chemoattractant activity of staphylococcal serine proteinase in vitro. Chemoattractant activity of staphylococcal serine proteinase. Antonie van Leuwenhoek 1988; 54: 85-87.

66. Le HV, Seeling GF, Syto R et al. Selective proteolytic cleavage of recombinant human interleukin-4. Evidence for a critical role of the C-terminus. Biochemistry 1991; 30: 9576-9582.

67. Arakawa T, Horan TP, McGinley M, Rohde MF. Effect of amino-terminal processing by Staphylococcus aureus V-8 protease on activity and structure of recombinant human interferon-gamma. J Interferon Res 1990; 10: 321-329.

68. Hasegawa N, Kondo I. Isolation and virulence of caseinaseand bound coagulase-deficient mutant of Staphylococcus aureus BB. $J$ Infect Dis 1984; 149: 538-843.

69. Todd JK, Frano-Buff A, Lawellin DW, Vasil ML. Phenotypic distinctiveness of Staphylococcus aureus strains associated with toxic shock syndrome. Infect Immun 1984; 45: 339-344.

70. Sanford BA, Thomas VL, Ramsay MA, Jones TO. Characterization of clinical strains of Staphylococcus aureus associated with pneumonia. J Clin Microbiol 1986; 24: 131-136.

71. Arai K, Muto T, Yamasa M, Yokota S. Effect of the passage and storage of strains and inoculum size on the change of zone pattern types and sizes produced by protease of MRSA. Jpn $J$ Assoc Infect Dis 1993; 67: 629-634.

72. Hudson SJ, Freeman R, Burdess D, Cookson BD. Crystal violet reactions of Staphylococcus aureus strains colonizing infants in the first six weeks. Epidemiol Infect 1993; 110; 79-86. 